\title{
Symptom expression of Phytophthora colocasiae in inoculated taro corms
}

\author{
Amy Maslen-Miller ${ }^{1}$, Robert A. Fullerton ${ }^{2}$, Angelika Tugaga ${ }^{1}$, Faalelei Tunupopo ${ }^{3}$, Seeseei Molimau- \\ Samasoni ${ }^{1}$, Joanna K. Bowen ${ }^{2}$, Robin M. MacDiarmid ${ }^{2,4}$ and Joy L. Tyson ${ }^{2, *}$ \\ ${ }^{1}$ The Scientific Research Organisation of Samoa, PO Box 6597, Apia, Samoa \\ ${ }^{2}$ New Zealand Institute for Plant \& Food Research Limited, Private Bag 92169, Auckland, \\ New Zealand \\ ${ }^{3}$ Ministry of Agriculture and Fisheries, PO Box 1874, Apia, Samoa \\ ${ }^{4}$ School of Biological Sciences, University of Auckland, Private Bag 92019, Auckland, New Zealand \\ *Corresponding author: Joy.Tyson@plantandfood.co.nz \\ (Original submission received 25 July 2019; accepted in revised form 19 December 2019; published online 27 January 2020)
}

\begin{abstract}
Taro leaf blight (TLB), caused by Phytophthora colocasiae, is normally characterised by leaf lesions. There are isolated reports of $P$. colocasiae causing a corm rot but the symptoms are not well defined and have not been recorded in Samoa. Here we report on an inoculation method and describe the symptoms of corm rot caused by $P$. colocasiae. In this study, a corm inoculation method was developed in physical containment laboratories in New Zealand and subsequent symptom development studies were undertaken on TLB-tolerant taro cultivars in Apia, Samoa. The Samoan TLB-tolerant taro cultivars were able to be wound-infected with $P$. colocasiae and the results confirm previous descriptions of $P$. colocasiae infection giving rise to light brown firm rots in corms. This work has allowed the pictorial record of corm rots to be updated, potentially providing for better distinction between corm rots caused by P. colocasiae and those caused by other pathogens, such as Fusarium spp.
\end{abstract}

Keywords Colocasia esculenta, taro leaf blight, pathogenicity, corm rot assay, Samoa

\section{INTRODUCTION}

Prior to 1993, taro (Colocasia esculenta) was a major export commodity for Samoa, with markets in New Zealand, Australia and the USA. In 1993, an incursion of taro leaf blight (TLB, caused by Phytophthora colocasiae) destroyed all taro crops, causing local food shortages and halting exports (Hunter et al. 1998). Regional breeding programmes have since produced new taro cultivars with significant tolerance to the disease. Local supply has been restored and the export market is expanding (Singh et al. 2012).

TLB is characterised by leaf lesions, which may coalesce to destroy large areas of lamina (Singh et al. 2012). Since the disease was first recorded in Indonesia in 1900 by Raciborski (Packard 1975), there have been isolated reports of $P$. colocasiae causing rot in taro corms; however, symptom descriptions differ widely. Butler and Kulkarni (1913) recorded 'dry rots' on $C$. antiquorum (= C. esculenta), and Gomez (1925) described a 'soft rot' of corms in the Philippines. Jackson and Gollifer (1975) described corm rots on C. esculenta 'Akalomamale initoa' in the Solomon Islands as "light brown, firm, often with a distinct margin". Uchida and Trujillo (2015) found that the rot in taro corms in Hawai'i was faint tan in colour and 'rubbery', later becoming brown to purplish with no distinct border and difficult to detect externally. These differences in symptoms may be the result of observations on different Colocasia species, or the consequence of mixed infections. Although TLB has been present in Samoa since 1993, corm rots caused by $P$. colocasiae have not been recorded under natural conditions in Samoa.
The only detailed study of $P$. colocasiae corm rots is that of Jackson and Gollifer (1975). In that study, no symptoms developed when pre-harvest corms were inoculated either by mycelial plugs in wounds or by sporangial suspensions applied to the surface of corms, however, the corms could be artificially infected through wounds after harvest. Phytophthora colocasiae was able to infect corms naturally through the wounds caused when cormels and roots were removed after harvest. Copper oxychloride sprays applied during the growing season controlled leaf infection and subsequent storage rots.

To our knowledge the only published figures of $P$. colocasiae corm rot of taro are those given in Jackson and Gollifer (1975). They are in black and white and it is not possible to distinguish fine detail of the symptoms.

In this study, a corm inoculation method was developed in physical containment laboratories in New Zealand $(P$. colocasiae is absent from New Zealand) based on the methods used by Jackson and Gollifer (1975) for P. colocasiae on taro, and those of Rojas et al. (2014) for P. infestans on potatoes.

\section{MATERIALS AND METHODS}

Method development in New Zealand

From December 2015 through to January 2016, pink-fleshed taro grown in Samoa (25 corms), and white-fleshed taro grown in Fiji (40 corms) were sourced from vegetable stores in Auckland, New Zealand. The cultivar names are unknown, and will be referred to hereafter as Samoan pink and Fijian white; however, the Samoan cultivar is likely to have been Talo Salani and the Fijian cultivar is likely to have been 'Niue' 
(known in Fiji as Tausala ni Samoa).

Corms of similar size and free from surface damage or visible rots were selected. Surface soil was removed from corms and the corm surface sterilised by submersion in $3 \%$ sodium hypochlorite $(\mathrm{NaOCl})$ for 30 minutes and then rinsed twice in sterile water.

Phytophthora colocasiae isolate Pc60, originally collected from leaves of taro in Sikkim, India in 1998, was used as inoculum. The culture was grown on V8 juice agar (Hine \& Aragaki 1963) at room temperature (c. $21^{\circ} \mathrm{C}$ ) under natural light for $5 \mathrm{~d}$ before use. The isolates used in this study are held in long-term storage in the New Zealand Institute for Plant \& Food Research (Mt Albert, Auckland) Phytophthora colocasiae culture collection.

Six plugs of corm tissue 10-20 mm deep were removed from each corm with a sterile 5 -mm diameter cork borer. Wounds were made on opposite sides of the corm in the apex, middle and basal regions of the corms (Fig. 1). Four wounds were inoculated with a 5-mm diameter plug of agar taken from the edge of a $P$. colocasiae colony. Two wounds on each corm were inoculated with a sterile plug of V8 juice agar and served as controls. For each inoculation site, the plug of corm tissue was returned and sealed with petroleum jelly (Vaseline, USA).

For comparison with mycelial inoculation, five additional corms of each taro cultivar were inoculated with a sporangial suspension produced by flooding 5-day-old cultures with sterile water. Corms were inoculated with $0.2 \mathrm{~mL}$ sporangial suspension (c. $2 \times 10^{3}$ sporangia/mL) in a similar manner, with two controls of sterile water.

After 7 days of incubation in a dark humid chamber at room temperature $\left(\right.$ c. $\left.21^{\circ} \mathrm{C}\right)$, the inoculated corms were cut transversely though each inoculation site and examined for rots.

Where symptoms were observed, isolations were made from representative lesions onto a selective medium, modified from Jeffers and Martin (1986), consisting of corn meal agar (CMA; Difco, MI, USA) amended with $2 \mathrm{mg} / \mathrm{L}$ carbendazim, $250 \mathrm{mg} / \mathrm{L}$ ampicillin, $10 \mathrm{mg} / \mathrm{L}$ rifampicin, 5 $\mathrm{mg} / \mathrm{L}$ pimaricin and $100 \mathrm{mg} / \mathrm{L}$ pentachloronitrobenzene (CARPP medium) (Tyson et al. 2014). Isolations were incubated at room temperature (c. $21^{\circ} \mathrm{C}$ ).

\section{Symptom development studies in Samoa}

In March 2018, freshly harvested corms of three TLBtolerant taro cultivars, Talo Fusi, Talo Salani and Samoa 2 (also known as Samoa lua), were sourced from Fugalei market in Apia, Samoa. Corms were selected, prepared and inoculated using the corm inoculation methodology developed in this study.

Due to biosecurity concerns, P. colocasiae isolate Pc96, originally from leaves of Samoa 2 collected from Malaemalu, Samoa in 2015, was used as inoculum for the Samoan infection studies. Incubations for inoculum growth and corm infection were at laboratory temperature (c. $27-30^{\circ} \mathrm{C}$ ) for $7 \mathrm{~d}$. Six corms of each cultivar were used for the infection and symptom development studies, and the experiment was repeated twice.

Corm rots were measured with a ruler from the base of the wound, directly inwards to the edge of the rot (as indicated in Fig. 2). Results were analysed using Analysis of Variance (ANOVA). Differences between individual treatments were

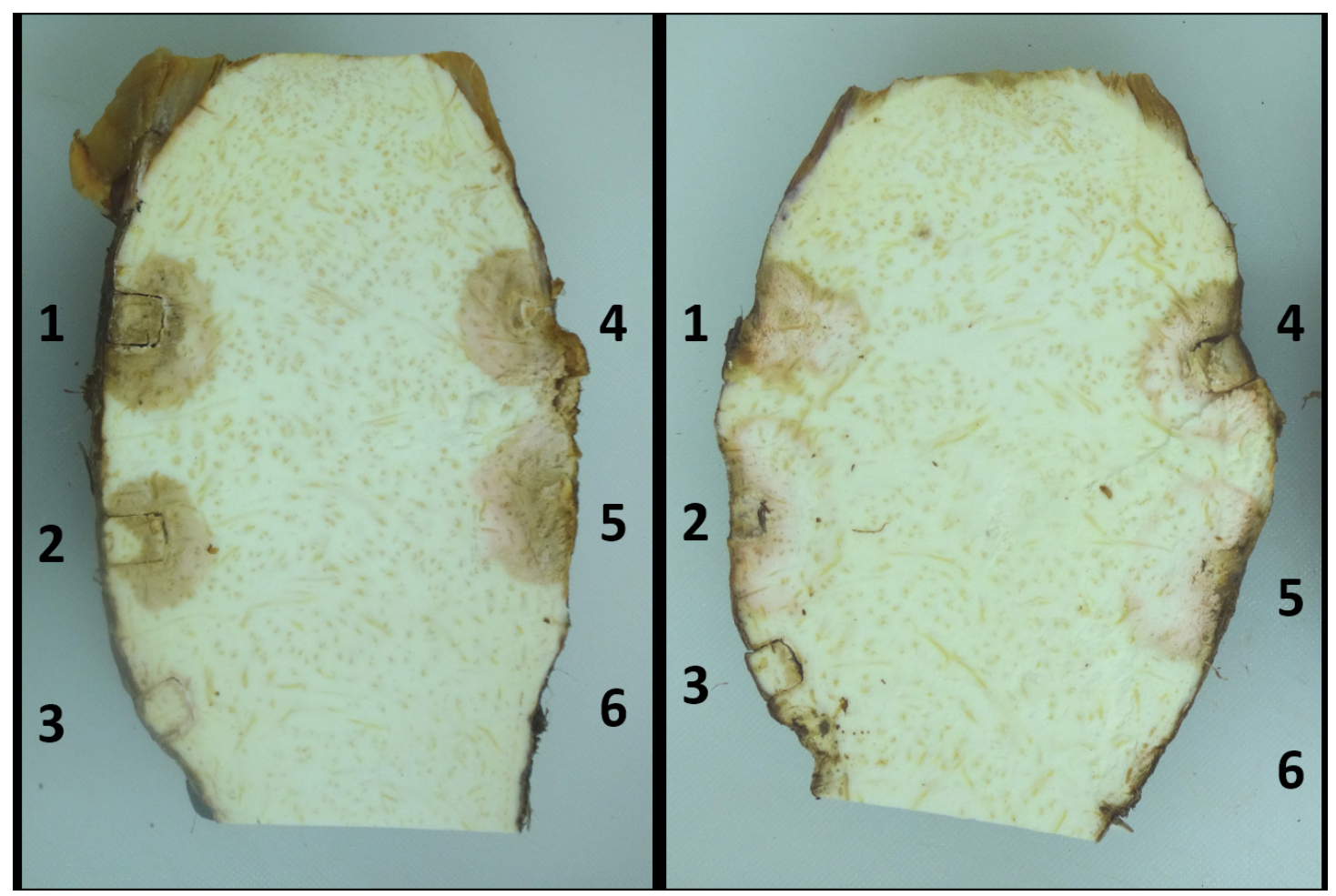

Figure 1 Transverse sections of Samoan pink taro corms, inoculated with Phytophthora colocasiae. Locations 1, 2, 4, 5 inoculated with isolate Pc60. Control locations 3 and 6 inoculated with a clean V8 juice agar plug and empty, respectively. 
determined using Fisher's Least Significant Difference (LSD, $\mathrm{P}=0.05)$. All analyses were conducted using Minitab version 16.

Where symptoms were observed, isolations were made from the margins of representative lesions onto CARPP medium and incubated at room temperature $\left(27-30^{\circ} \mathrm{C}\right)$.

\section{RESULTS}

\section{Method development}

The mycelial inoculation method was successful in initiating rots in corms imported into New Zealand. Rots in Samoan pink were tan and firm, sometimes with light pink areas and often with an irregular brown margin (Fig. 1); rots in Fijian white were similar, with irregular, diffuse margins, although occasionally a darker brown. No symptoms were seen at any of the control inoculation points. Inoculations with sporangia did not result in consistent corm infection, suggesting that a high inoculum load is needed for infection; therefore mycelial plugs were used in subsequent symptom development studies undertaken in Samoa.

\section{Symptom development studies}

The inoculation of corms in Samoa with mycelial plugs successfully initiated rots in all three cultivars. $P$. colocasiae was re-isolated from representative lesions and identified

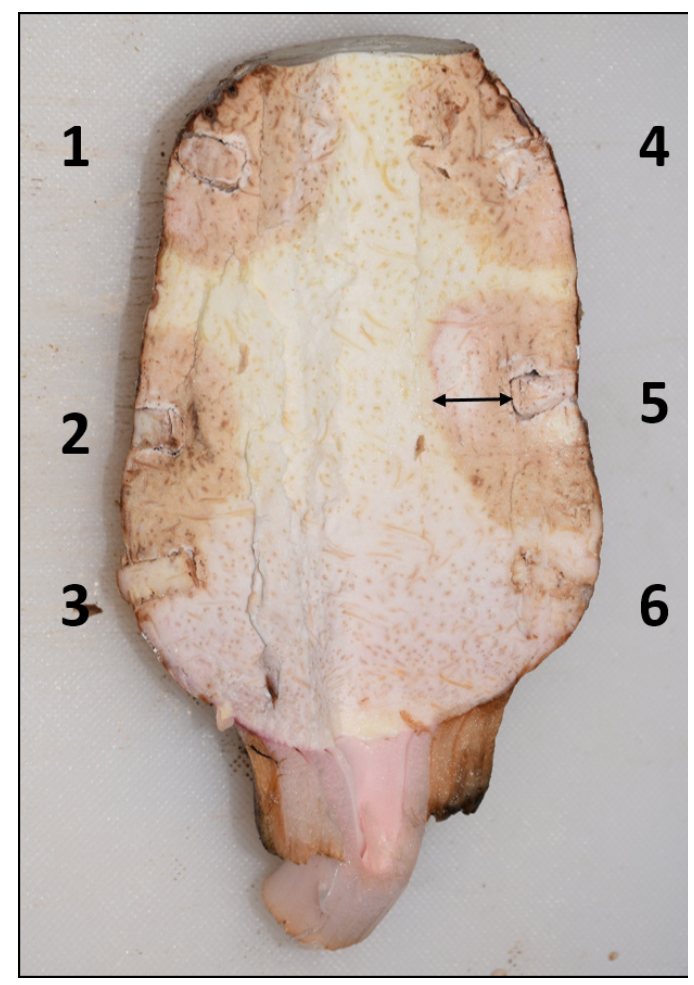

Figure 2 Transverse section of Phytophthora colocasiae inoculated taro corm of Talo Salani. Locations 1, 2, 4, 5 inoculated with isolate Pc96. Location 3 inoculated with a clean V8 juice agar plug, Location 6 empty. The double-ended arrow indicates where lesion measurements were taken. using standard morphological techniques, satisfying Koch's postulates. The control inoculations did not develop rots. Rots were clearly visible on the surface of the corm as darker brown patches centred on the inoculation sites (Fig. 3).

Internally, rots in corms of Talo Salani were firm and light brown with indistinct margins, sometimes with light pink areas, and irregular dark vascular strands extending from the rot into the healthy flesh (Fig. 2). Occasionally the asymptomatic flesh in advance of the rot had a yellow tinge. Rots became darker brown over time. The rots in Talo Fusi were similar, although sometimes being a darker brown initially, with yellowing of tissue in advance of the rot. There was a significant difference in the rate of colonisation between Talo Fusi and Talo Salani (Table 1).

\section{DISCUSSION}

The inoculation method developed in this study was successful in initiating corm rots in taro. The symptoms induced on the cultivars of taro used here confirm the descriptions of Jackson and Gollifer (1975) and Uchida and Trujillo (2015) of $P$. colocasiae infection giving rise to light brown firm rots. This work has allowed the pictorial record of corm rots to be updated, potentially providing for better distinction between corm rots caused by $P$. colocasiae and those caused by other pathogens found in Samoa, for example Pythium spp., Botryodiplodia theobromae and Sclerotium rolfsii (Gerlach 1988). Pythium spp. cause a distinctive dry crumbly white rot with a sharply defined margin (Jackson \& Gollifer 1975), B. theobromae causes a spongy rot that becomes dark-blue to black as it progresses (Ooka 1990) and $S$. rolfsii results in a brown rot that is accompanied by brown sclerotia and white mycelial strands on the surface (Gerlach 1988).

This study has shown that the appearance of the symptoms and the rate of colonisation of corm tissue by the two Phytophthora colocasiae isolates used are influenced by taro cultivar but further work is required to determine whether these results are representative of $P$. colocasiae in general or these isolates only. Also , care should be taken in comparing the results of the method development experiment with the Samoan infection studies as a different isolate was used in each case. All the cultivars used in the infection studies in Samoa were selected for commercial production on the basis of both acceptable agronomic characters and a high degree of tolerance to TLB. Informal surveys and observations of commercial crops (Tolo Iosefa, Samoa MAF, pers. comm.) have suggested that Talo Fusi consistently has less leaf infection than Talo Salani. That difference was not reflected in the rates of colonisation of the inoculated corms of the two cultivars in the current study.

The infection of taro corms under natural conditions appears to berare. Over the past $110+$ years since $P$. colocasiae was first described, there have been only six primary records of its occurrence in corms (Butler \& Kulkarni 1913; Gomez 1925; Jackson \& Gollifer 1975; Kulkarni \& Sharma 1975; Packard 1975; Uchida \& Trujillo 2015). Phytophthora colocasiae has been present in Samoa for 25 years yet there has been no record of it causing corm rots.

In Solomon Islands, Jackson and Gollifer (1975) found that rots developed on corms when cormels, roots and 


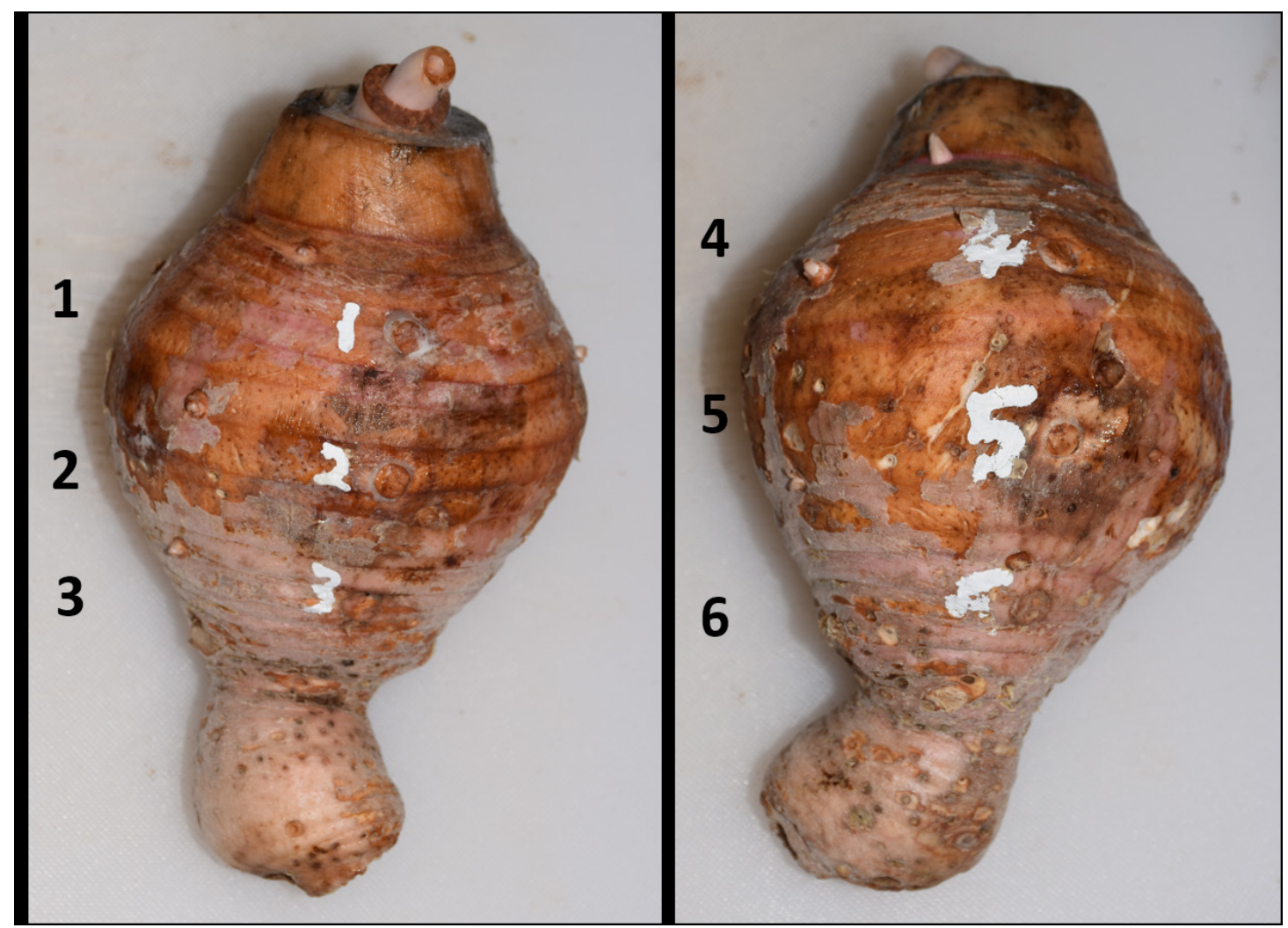

Figure 3 Phytophthora colocasiae corm inoculations of Talo Salani, Samoa, February 2018. Locations 1, 2, 4, 5 inoculated with isolate Pc96. Location 3 inoculated with a clean V8 juice agar plug, Location 6 empty.

debris were removed at harvest. The rots observed at the apex of the corm were thought to have been initiated when the leaf was removed from the corm at harvest. It is likely that sporangia formed on the leaves was the inoculum source for corm rot in the Solomons. However, Phytophthora species can also be capable of producing oospores.

Phytophthora colocasiae is a heterothallic species, only able to produce the more durable, long-lived oospores by the pairing of two compatible mating types $\left(\mathrm{A}^{1}\right.$ and $\mathrm{A}^{2}$ ) (Ko 1979; Ann et al. 1986). However, re-surveying of the mating types of $P$. colocasiae in Taiwan (2006-2007) revealed seven homothallic isolates $\left(\mathrm{A}^{1} / \mathrm{A}^{2}\right)$ that were able to form oospores in pure culture (Lin \& Ko 2008). Studies by Tyson and Fullerton (2007) showed that in 1998 there was only one mating type $\left(\mathrm{A}^{2}\right)$ present in Samoa. More recently Mellow et al. (2018), working with 54 isolates of $P$. colocasiae collected from the field in Samoa in 2015, confirmed that there had been no change, and $\mathrm{A}^{2}$ remained the only mating type in the

Table 1 Average extension (mm) of $P$. colocasiae rots into taro corms $7 \mathrm{~d}$ after inoculation in each trial $(n=24)$. Values with similar letters are not significantly different, $\mathrm{P}=0.05$.

\begin{tabular}{|c|c|c|}
\hline Taro cultivar & \multicolumn{2}{|c|}{ mean lesion depth (mm) } \\
\hline & Trial 1 & Trial 2 \\
\hline Talo Fusi & $9.1 \mathrm{a}$ & $15.3 \mathrm{a}$ \\
\hline Samoa 2 & $6.8 \mathrm{ab}$ & $12.6 \mathrm{ab}$ \\
\hline Talo Salani & $5.9 \mathrm{~b}$ & $9.8 \mathrm{~b}$ \\
\hline
\end{tabular}

country. In both studies, none of the Samoan isolates formed oospores when paired between themselves, confirming that the Samoan P. colocasiae population is heterothallic. As a consequence, oospores are unlikely to be produced in Samoa and form a source of soil-borne inoculum. The only inoculum available for natural infection of corms by $P$. colocasiae in Samoa is likely to be sporangia, produced on leaves, being deposited on the corm during and after harvest. The extent to which this may occur naturally in Samoa, either in the field or at harvest, and the conditions that might favour it, are the subjects of further study.

\section{ACKNOWLEDGEMENTS}

Funding for this project was provided by Bio-Protection Research Centre (New Zealand), Pacific Horticultural and Agricultural Market Access (PHAMA) and the Australian Centre for International Agricultural Research (ACIAR). Thanks are given to the Samoa Ministry of Agriculture and Fisheries (MAF) for assistance with collection of isolates.

\section{REFERENCES}

Ann PJ, Kao CW, Ko WH 1986. Mating-type distribution of Phytophthora colocasiae in Taiwan. Mycopathologia 93: 193-194.https://doi.org/10.1007/BF00443524

Butler EJ, Kulkarni GS 1913. Colocasia blight caused by Phytophthora colocasiae Racib. Memoirs of the Department of Agriculture, India 5: 223-259.

Gerlach WWP 1988. Plant diseases of Western Samoa. Eschborn, Germany, Samoan German Crop Protection Project. 215 p. 
Gomez ET 1925. Leaf blight of Gabi. Philippine Agriculturist 14: 429-440. https://doi.org/10.1016/S00225347(17)73526-4

Hine RB, Aragaki M 1963. Pathogenicity, vitamin nutrition and cultural characteristics of isolates of Phytophthora parasitica from carnation and other hosts in Hawaii. Phytopathology 53: 1194-1197.

Hunter D, Pouono K, Semisi S 1998. The impact of taro leaf blight in the Pacific Islands with special reference to Samoa. Journal of South Pacific Agriculture 5: 44-56.

Jackson GVH, Gollifer DE 1975. Storage rots of taro (Colocasia esculenta) in the British Solomon Islands. Annals of Applied Biology 80: 217-230. https://doi. org/10.1111/j.1744-7348.1975.tb01625.x

Jeffers SN, Martin SB 1986. Comparison of two media selective for Phytophthora and Pythium species. Plant Disease 90: 1038-1043. https://doi.org/10.1094/PD70-1038

Ko WH 1979. Mating-type distribution of Phytophthora colocasiae on the island of Hawaii. Mycologia 71: 434437. https://doi.org/10.1080/00275514.1979.120210 21

Kulkarni SN, Sharma OP 1975. Corm rot of Colocasia antiquorum Schoff, due to Phytophthora colocasiae Sacc. JNKVV Research Journal 9: 70.

Lin MJ, Ko WH 2008. Occurrence of isolates of Phytophthora colocasiae in Taiwan with homothallic behavior and its significance. Mycologia 100: 727-734. https://doi. org/10.3852/08-070

Mellow KD, Tyson JL, Fullerton RA, Tugaga A, Tunupopo F, Maslen-Miller A 2018. Mating types of Phytophthora colocasiae on the island of Upolu, Samoa. New Zealand Plant Protection 71: 289-292. https://doi. org/10.30843/nzpp.2018.71.143

Ooka JJ 1990. Taro diseases. Research Extension Series, Hawaii Institute of Tropical Agriculture and Human Resources 114: 51-59.

Packard JC 1975. The Bougainville taro blight. Pacific Islands Studies Program, Miscellaneous Work Papers. Honolulu, University of Hawai'i. 144 p.

Rojas JA, Kirk WW, Gachango E, Douches DS, Hanson LE 2014. Tuber blight development in potato cultivars in response to different genotypes of Phytophthora infestans. Journal of Phytopathology 162: 33-42. https://doi.org/10.1111/jph.12153

Singh D, Jackson G, Hunter D, Fullerton RA, Lebot V, Taylor M, Iosefa T, Okpul T, Tyson JL 2012. Taro leaf blight - a threat to food security. Agriculture 2: 182-203. https:// doi.org/10.3390/agriculture2030182

Tyson JL, Fullerton RA 2007. Mating types of Phytophthora colocasiae from the Pacific region, India and South-east Asia. Australasian Plant Disease Notes 2: 111-112. https://doi.org/10.1071/DN07046

Tyson JL, Taylor RK, Curtis CL, Manning MA 2014. A preharvest rot of persimmon fruit caused by Phytophthora cactorum in New Zealand. Australasian Plant Disease Notes 9: 122. https://doi.org/10.1007/s13314-0130122-x
Uchida JY, Trujillo EE 2015. Phytophthora colocasiae. Retrieved 19 January 2015, from http://www.extento. hawaii.edu/kbase/crop/type/p_coloc.htm 